Адрес статьи / To link this article: http://cat.ifmo.ru/ru/2016/v1-i1/57

\title{
Формирование современных информационных идеалов
}

\author{
А.С. Дриккер, Е.А. Маковецкий \\ Санкт-Петербургский государственный университет, Россия \\ a.drikker@spbu.ru, e.makovetsky@spbu.ru
}

\begin{abstract}
Аннотация. Сегодняшний идеал передовой прогрессивной культуры - это информационный идеал, который пропагандирует будущее общество знания. Построение информационного общества обозначено одной из главных целей в конституциях ряда стран. Однако анализ постиндустриальной культуры глобального мира не позволяет обнаружить убедительные признаки прокламируемого будущего, скорее он обнаруживает очевидные расхождения деклараций и реальности. Базовая ценность компьютеризированного мира - не знание, а все та же собственность, обретение которой теперь непосредственно связано с интеграцией в системы манипулирования информацией, определяющей течение массовых процессов. Ошибочная трактовка актуальных тенденций — следствие редукции, в ходе которой информация и знание рассматриваются как синонимы. Не количество информации определяет восходящую эволюцию, а значимая информация (Винер), трансформируемая в знание. Эффективный прогноз не может строиться преимущественно на технологической базе, эволюция культуры есть результат совокупности социальных, психологических и технологических процессов.

В то же время информационные технологии стоят особняком: если орудия, механизмы первично воздействовали на окружающую среду и порождали перемены социальные, то цифровые технологии способны влиять непосредственно на сознание, на человека. На современном уровне прогресса информационно-коммуникационные технологии создают предпосылки для смены приоритетов социальных на индивидуальные для того, чтобы открыть за животными, общественными потребностями (удовлетворение которых обеспечивали технологии традиционного и индустриального общества) истинно человеческие.

Компьютеризацию, распространение глобальных сетей, виртуальных расширений можно расценивать как окончание ледникового периода. Новые цифровые «климатические» культурные условия открывают путь к недостижимому пока самопознанию. А вот на горизонтах этого самопознания появляется вожделенное общество знания.
\end{abstract}

Ключевые слова: информационно-коммуникационные технологии; важная информация; онтология; культурная эволюция; постиндустриальная культура; информационное общество.

Сегодняшний идеал передовой прогрессивной культуры - это, безусловно, информационный идеал. Информационные технологии (IT) в настоящее время являют собой раскаленное ядро актуальной культуры, а их производные - Интернет, социальные сети, мобильные устройства, компьютеры и программные продукты - атмосферу, определяющую развитие современности. Представить жизнь молодого поколения вне цифровой среды так же невозможно, как французскую академию наук без книг. Всеобщая компьютеризация за считанные десятилетия изменила условия жизни сильнее, чем предшествовавшие века пара и электричества... 
Мир во всех своих удивительных проявлениях открыт практически для каждого, все блага культуры куслугам рядового гражданина, возможности для совершенствования и познания безграничны. И не удивительно, что построение информационного общества обозначено одной из главных целей в конституциях целого ряда стран.

В то же время, несмотря на стремительное увеличение производительности процессора, экспоненциальный (закон Мура) рост объемов памяти, болезни и проблемы докомпьютерной эры никуда не делись: имущественное неравенство усиливается, в Африке и Азии миллионы голодают, в вооруженных конфликтах ежегодно гибнут десятки тысяч человек... И даже в сверхблагополучных странах золотого миллиарда на фоне поразительных достижений люди не стали радостней, ощущение счастья оказывается весьма слабо коррелировано с валовым доходом на душу населения [1] и уровнем компьютеризации.

В чем же дело? Что означают негативные тенденции, достаточно распространенные на всех широтах и меридианах информационного мира? Это некие флуктуации прогрессивного течения, временные издержки? Или они носят системный характер, и информационное ускорение нуждается в коррекции?

\section{Базис информационного общества}

Конечно, люди теперь живут дольше, люди живут лучше. Хотя и с этим позитивом не все так просто. Еще полтора столетия назад, характеризуя родное американское жизнеустройство, Эмерсон отмечал: «Вещи оседлали человека и гонят его вперед». Но человеку не нравится числиться по «обществу потребления», ему требуется ощущать себя кем-то повыше. Однако религия, социально-философские концепции, в частности, либерализм, связанный с победной экспансией западной цивилизации, сегодня утратили пассионарность; лозунги и идеалы, когда-то вдохновлявшие реформацию и революции, лишились былой привлекательности.

Именно в такой среде появляется, открывая широчайшие перспективы, компьютер, а западные футурологи начинают активно разрабатывать и продвигать идеи нового общества, «информационной» культуры. Эта культура имеет мало общего с установками рыночного общества: информация (в отличие от материи и энергии) не убывает в процессе потребления, что открывает поистине волшебные возможности. Каковы же принципиальные основы общества будущего?

Первое - это центральная роль теоретической науки. «Машины как наиболее важная часть капитала вытесняются теоретическим знанием», - говорит Д. Белл [2]. Теперь наука используется «для получения нового знания, тогда как прежде - для совершенствования орудий производства и новых форм его организации», — дополняет П. Дракер [3].

Второе - новые интеллектуальные технологии. Технологии едва ли не всесильные, благодаря «кодификации знаний в абстрактные своды символов, которые могут быть использованы для изучения самых разных сторон опыта» [2, с. 25].

Третье - формирование нового общественного класса — носителя знания. Причем этот класс будет играть доминирующую роль, ибо информация и знания становятся важнейшей составляющей капитала [4].

Убедительность этих прогнозов и теорий поддерживается масштабом и скоростью информационного наступления (умножением мощности вычислительных устройств, совершенствованием глобальных сетей, поразительным расширением спектра их функций [5]). Теперь уже не постиндустриальные проблемы, а «общество знания» активно обсуждается и на благополучном Западе, и в не слишком продвинутых странах третьего мира. Декларации, подобные следующей, становятся крайне популярными: «Сегодня один человек узнает за один день больше, чем его предки, жившие в саванне, узнавали за всю жизнь. Поколение 2000-го года, в свою очередь, будет знать в 40 раз больше, чем поколение 60-х» [6, с. 140].

Небывалый технологический прогресс буквально во всех сферах (от бытового устройства до космических исследований) дает такому энтузиазму конкретные основания, а пионерские проекты обещают (например, в рамках нано-, био-, инфокогнитивной конвергенции) в короткое время фантастические перемены. Декларации, согласно которым корпорации «как центры 
социального авторитета [вытесняются, - А.Д.] университетскими и исследовательскими институтами» [2], а в обществе торжествуют «постматериальные» ценности, воспринимаются как констатация пусть не сегодняшнего, но завтрашнего состояния дел. Причем общий энтузиазм, поддерживаемый мощными проектами Google, Apple, Intel, вдохновляемый идеями К. Вентера и Р. Курцвейла, за полстолетия после первых работ провозвестников информационной эры, пожалуй, лишь возрастает.

Однако следует посмотреть пристально, действительно ли в ходе технологического прорыва трансформируются базисные общественные установки. Или, быть может, пламенные идеи рождают некие оптические аберрации.

\section{Информация и знание}

Начнем с фундамента. Да, скорости информационных потоков в оптоволоконных и спутниковых каналах потрясают воображение, а объемы передаваемой информации прямо-таки безграничны. Но информация это еще не знание, в лучшем случае - сведения. Да, компьютерная картинка, воспроизводимая с высоким разрешением на мониторе, несет информации в тысячи раз больше, чем «Гамлет», но лишь пока мы говорим о технической переработке информации, имеющей с обретением знания самое поверхностное сходство. Сенсорное восприятие еще не характеризует изменения аккумулирующего аппарата - сознания; от доступности знания очень далеко до способности его восприятия и усвоения.

Смелый прогноз - увеличение знания от поколения к поколению в десятки раз, появление миллионов фантастически эрудированных энциклопедистов - предполагает перестройку центральной нервной системы, в первую очередь, увеличение объема оперативной (кратковременной) памяти. Но она, увы, неизменна уже на протяжении многих тысяч лет. Сравнение интеллекта Сократа или Эйнштейна, не знакомых с компьютером, с интеллектом системного администратора выглядит анекдотично.

Опыт стремительного технологического прогресса в предшествующих столетиях также не дает особых надежд на заметный культурный подъем. Развитие полиграфии, телефонии, телевидения, обеспечивая заметное увеличение скорости передачи информации, способствовало, например, стремительному распространению грамотности, но трудно сказать, что поколение 1980-х в 40 раз образованнее поколения 1940-х и в 1500 раз (!) просвещеннее поколения 1900-х.

Перейдем к фундаментальной науке. С одной стороны, сегодня фундаментальная наука (происхождение Вселенной и человека, преследование загадочных бозонов на коллайдере...) широко рекламируется и весьма активно обсуждается. С другой, фундаментальных научных открытий XX век породил немного больше, чем XIX, несмотря на эволюционное культурное ускорение. А общественную значимость науки достаточно красноречиво характеризует прагматичный критерий: годовой доход ведущего менеджера (одного из армады) превышает Нобелевскую премию за уникальный вклад в науку. А вот роль прикладных наук, напротив, постоянно возрастает: кумиры современности Стив Джобс и Марк Цукерберг. Так что «превознесение бытия превыше знания» [7, с. 304] продолжается и усиливается.

Возможно, что следует говорить о переменах более важных, связанных с человеком, с психологией. Идеологи общества знания много внимания уделяют новому классу - носителю знания. Кто же эти люди будущего?

Они определены как «класс интеллектуалов», что сразу удивляет. Интеллект характеристика личностная, а классовый признак определяется социальной стратификацией, формой собственности, участием в распределении общественного продукта. Однако это не оговорка или небрежное употребление термина. Новые «интеллектуалы» - именно класс, для представителей которого объектом собственности являются некие знания, рассматриваемые как капитал [4]. Причем владение таким капиталом делает этот класс доминирующим ввиду возрастающей сложности информационного общества.

Ярлык технократов не отвечает претензиям новой элиты, сегодня они - представители общества знания, которых отличают профессионализм, инициативность, имущественный и социальный статус, стремление к творческой самореализации.

International Culture \& Technology Studies, Vol. 1, No. 1 
Набор рекламируемых качеств вызывает только восхищение. Можно ли найти более демократичный путь к власти, чем способность «усваивать информацию и генерировать знание»? Правда, настораживает, что расслоение между высшим классом богатых носителей «постэкономических ценностей» [8] и низшим классом бедняков, занятых трудом не столь престижным [4], лишь усиливается. Такое расслоение очевидно чревато серьезными проблемами.

Принадлежность к новому классу связывается (наконец-то!) не с происхождением, богатством и связями, а исключительно с личными способностями. Однако уже начальный пропуск в элиту (в престижные учебные заведения) по-прежнему, в первую очередь получают отпрыски состоятельных семейств. Быть может, они - редкие таланты в области фундаментальной науки? Ничуть не бывало: две трети нынешнего «интеллектуального» истеблишмента - экономисты, финансисты, юристы [4].

Обратим внимание на остающуюся в тени, возможно, важнейшую особенность культуры в демократической информационной фазе - массовость. Чтобы уровень знаний нарастал в обещанной геометрической прогрессии, необходимо столь же интенсивное наращивание креативных сеятелей знания. Но массовое культурное производство, к сожалению, неизбежно ориентировано на тиражирование, использование готовых моделей [9]. Резкое расширение числа производителей и пользователей сопровождается явным упрощением, редукцией культурных фильтров (снижением образовательного ценза, общего уровня широко распространенных источников знания). Демократичность знания, отвечающая запросам широкой аудитории, ставит под сомнение даже позитив доступности: приемник, в котором критерии отбора упрощаются, а фильтры практически отсутствуют, попросту забивается шумом.

Итак, планетарное постиндустриальное общество, оснащенное цифровыми технологиями, действительно характеризуется переработкой гигантских объемов информации. Однако усмотреть принципиальное изменение роли и уровня знаний достаточно сложно. Противоречия между декларациями и реальностью определяются редукцией, в ходе которой информация и знание рассматриваются как синонимы.

\section{Информация и аксиология}

Еще Фрэнсис Бэкон сказал: «Знание - сила». Правители его «Новой Атлантиды» были апостолами научно-технического прогресса, решавшего все проблемы жизни [10]. В.И. Ленин призывал «учиться, учиться и учиться». Однако с построением счастливой Атлантиды на этих основаниях дело почему-то не ладилось. Но может быть попытки не безнадежны? Актуальная культура, уяснив ценность знания и открыв прямой доступ к информационным богатствам, просто не успела еще найти пути и методы их плодотворного освоения. Когда не хлеб, не энергия, а знание [11] прокламируется в качестве высшей ценности, это уже само по себе ободряет и увлекает.

Однако констатация крайне высокого статуса знания в постиндустриальной культуре вызывает сомнение. Объем информации, доступной бушмену, кочующему по Калахари, и современному тинейджеру, конечно, несравним. Но можно ли сопоставить ценность первобытного знания, позволявшего добывать огонь и отыскивать воду среди пустыни, с ценностью знания бакалавра в области менеджмента?

Далее, что лежит в основе трудов адептов информационного общества, когда они говорят о «знании-капитале», об инструменте, обеспечивающем «социальный статус», о новом «эквиваленте собственности»? Ценность знания определяется в конечном итоге путем его конвертации в твердую валюту. Ошибка принципиальная, абстрактное знание не может направляться принципами утилитарными.

Но даже в рамках этой достаточно сомнительной конвертации возникает вопрос: отчего же универсальный денежный эквивалент отмечает престиж учителя (важнейшего звена в системе передачи знания) не выше, чем сантехника? Образованность, которая так ценилась во все века, ныне стоит недорого. Сегодняшний университетский выпускник представляет отнюдь не элиту. К тому же Интернет позволяет любому юзеру без диплома и затрат использовать опыт уникальных эрудитов. Процесс девальвации знания налицо. 
Посмотрим на практические устремления новых «интеллектуалов»? Они тратят сотни тысяч долларов в университетах за приобщение к «постматериальным» идеалам, но эти траты оборачиваются миллионными выигрышами при успешном карьерном росте. Список «интеллектуалов» из высшего руководства крупных компаний и их фантастические доходы вызывают невольную догадку: «постматериальная ценность» — это очень большие деньги.

Можно приветствовать желание навести некий «интеллектуальный флер», выбрать красивый ориентир, однако этот камуфляж затушевывает безрадостную реальность. Поклонение золотому тельцу (которое не удалось искоренить ни Моисею, ни вождям и жертвам многих революций) благополучно развивается на «информационной» почве.

Маститый экономист Дж. Гэлбрейт откровеннее А. Белла и 3. Бжезинского писал о стимуле развития нового мира: «Источником той энергии и инициативы, которые служат движущей силой современной экономики, является не просто жажда богатства, а желание превзойти других в его накоплении» [12, с. 493]. Н. Розенберг, автор книги «Как Запад стал богатым», обеспокоенный тем, что «общество более гуманное и сострадательное (в социальном и политическом плане), чем наше собственное, ... уменьшит способность будущих поколений наращивать уровень материального благосостояния» [13], тревожился напрасно.

\section{Информационная опасность}

Согласно прогнозам Э. Тоффлера, информационное общество - «третья волна» (вслед за первой, сельскохозяйственной, и второй, индустриальной) - принесет новые отношения и ценности - новый строй жизни, основанный на возобновляемых источниках энергии и новых методах производства, на новых принципах организации семьи, школы и общественных союзов [11]. Компьютер и глобальные сети вроде бы способствуют следующему витку эволюции, но пока общество оплачивает успешного топ-менеджера деньгами, которые могли бы (теоретически) спасти от голодной смерти десятки тысяч жителей Эфиопии, приходится признать КПД информационного механизма ничтожным. Столь неожиданный эффект победы демократии и информатики не может не вызывать опасений.

В 1960-70-е годы революционные идеи А. Белла и Э. Тоффлера вызвали всемирный резонанс. Однако их на четверть века опередил еще один американец - Дж. Бернем. В 1940 году, слыхом не слыхав об информационном обществе, он написал работу «Революция менеджеров». Вот содержание книги в кратком изложении Дж. Оруэлла.

«Правителями этого нового общества будут те, кто фактически контролирует средства производства: администраторы компаний, технократы, бюрократы и военные, которых Бернем объединяет под именем «менеджеров». Эти люди устранят прежний класс капиталистов, сокрушат рабочий класс и организуют общество таким образом, что власть иэкономические привилегии останутся в их руках. Права частной собственности будут отменены, но не будет и общественной собственности. Новый мир ...будет состоять из громадных сверхгосударств, сложившихся вокруг главных индустриальных иентров Европьи, Азии и Америки... Все они [государства - А.Д.] будут иерархическими: аристократия способных наверху и масса полурабов внизу» [14].

Дж. Бернем оказался весьма прозорливым. В 1940 году он наметил ядра трех сверхдержав: Япония, Германия, США. Именно его работа, судя по всему, подтолкнула Оруэлла к созданию антиутопии «1984». Вот и сегодня, когда показалось, что вблизи засиял путь к всеобщему процветанию, потенциал сверхтехнологичного тоталитаризма может поддерживаться за счет глобальных информационных проектов.

Удивительные достижения прогресса не сделали людей счастливее. Вероятно одна из главных причин этого - продолжающаяся на фоне информационного бума специализация знания. «Узкая специализация муравьев ...создает предпосылки для их более успешного обучения (быстрее других насекомых, а также земноводных, пресмыкающихся и многих птиц) ...и увеличивает шансы в борьбе за существование» [15, с. 28]. Новейшие технологии удивительный плод рациональной культуры. Однако вряд ли муравьиная эффективность прогрессивная адаптация, основанная на разделении знания и повышении производительности труда, отвечает человеческим идеалам.

International Culture \& Technology Studies, Vol. 1, No. 1 
Человек - существо неуловимо многомерное, его не описать в координатной сетке прогресса. Границы сегодняшнего мира раздвинулись, численность населения превысила семь миллиардов, скорости и объемы передачи данных возрастают экспоненциально. Но как использовать гигантскую пропускную способность цифровых каналов в интересах человека, пока остается загадкой.

\section{Технология и онтология}

Почему же информационный проект очевидно буксует, несмотря на удивительный потенциал? Высокая технологичность рациональной культуры обеспечила ее достижения и успехи. Но большая ошибка отводить технологии ведущую эволюционную роль. Технологии возникают не в космосе, а в социально-психологической среде, они активнейшим образом воздействуют на нее и испытывают ее давление. Технологии, в том числе и информационные, конечно, отражают эволюционные закономерности, но те ценности, для поддержания которых они востребованы, определяются общественной психологией и заказом.

Сегодняшний кризис религии, идеологии, философии оставляет пользователя компьютера в состоянии экзистенциальной растерянности. Смысл существования в эпоху оглушающих, ослепляющих технологических перемен для представителя цивилизованного общества, пожалуй, даже более загадочен, чем для человека средневековья.

А потому IT с их видимыми «сверхчеловеческими» возможностями поистине становятся для современного сознания больше чем технологией - религией, философией, они формируют идеалы, рисуют перспективы. Но эта картина создается по прагматичному заказу доминирующей цивилизации.

Как отмечал Н. Винер: «...значение имеет не количество посланной информации, а количество информации, которая может проникнуть в коммуникационные и аккумулирующие аппараты в достаточном количестве для того, чтобы служить в качестве раздражителя действия» [16, с. 101]. Пока информационный океан, открытый в глобальных сетях, еще не катализировал процесс аккумуляции и кристаллизации знания. Базовая ценность компьютеризированного постиндустриального мира - не знание, а все та же собственность, обретение которой теперь связано, в первую очередь, не с силой или капиталом, а с информационными возможностями, с участием в управлении массовыми социально-экономическими процессами. Модная теория «информационного общества» - лишь актуальная модификация ценностей прошлой эпохи, упрощенных в ходе демократизации. Подобная информационная редукция знания не способна вызывать действие, нацеленное на обновление культуры. Поэтому теория «информационного общества» видится пока очередной утопией, со всеми плюсами и минусами этого интеллектуального жанра.

\section{Информационные горизонты}

Стремительное вторжение цифрового мира в культуру связано со столь же эпохальными явлениями: демографическим бумом XX века и демократической революцией. Как сегодняшний товарный океан не может существовать без автоматизированных систем управления, так и глобальная культурная революция захлебнулась бы в одночасье без сетевой компьютерной среды.

Безусловно, демократизацию можно истолковывать как варваризацию. Перемены в текучей культурной среде можно сравнить с растеканием по широкому равнинному руслу реки, вырвавшейся из ущелья. Да, конечно, культура обмелела, но притоков стало много больше, а площадь водной глади необозрима. И подобные массовые условия создают возможности для эволюционного скачка.

Потенциал двоичного кода (являющегося базисным языком нейронного механизма, всей нервной деятельности, чувств и мыслей), столь велик, что подобный - абсолютно универсальный - электронный язык, пригодный «для изучения самых разных сторон опыта» и органично (как речь) доступный многомиллиардной популяции, способен произвести перемены более радикальные, чем письменность или печатный станок. Особенно если учесть, что базой для 
подобных перемен является многотысячелетнее культурное богатство, широко открытое и предлагаемое к актуальному использованию.

Все теории информационного общества (от Э. Тоффлера, А. Белла до К. Вентера, Р. Курцвейла), предложенные большими учеными, яркими личностями, отличает и некая наивность. Юношеский оптимизм Белла и Тоффлера преломился в сомнительную точность их социокультурных прогнозов (вместо ожидавшегося решительного снижения концентрации, стандартизации, специализации, централизации можно наблюдать их энергичное усиление в глобальном мире). Этот оптимизм был связан с недооценкой консервативной традиционной психологии, не только не сдавшей позиции, но успешно использовавшей информационную среду в своих корыстных целях.

Половина столетия, прошедшая с момента выхода первых работ Э. Тоффлера, казалось бы немалый срок. Идеи нынешних властителей умов пятьдесят лет назад виделись бы не более чем крутой научной фантастикой. Сегодня же К. Вентер, первым прочитавший геном человека, пусть и с большой долей рекламности, описывает достаточно детальный и конструктивный план телепортации инопланетной (или иногалактической) жизни на Землю. А отец сканера и синтезатора $\mathrm{P}$. Курцвейл прогнозирует использование нанороботов для расширения возможностей мозга.

Блестящие пропагандисты информационного общества новой волны видят одной из центральных задач движение к бессмертию. Но и 3D-принтер для жизни (К. Вентер [17]) и нанороботы Курцвейла [18] - производные прагматичной культуры. В этой модели вечная идея бессмертия, упрощаясь, превращается в проект непосредственной борьбы с физическим угасанием. При этом из ряда главных задач познания вытесняется фундаментальная проблема бытия - его конечность, вне которой нет места для человечности и гуманизма. Культура опять-таки сворачивает на путь редукции.

Однако в недрах культуры, убегающей от смерти, формируются предпосылки иного пути. Технологический потенциал как функция воображения поистине безграничен и способен ответить самым фантастическим людским запросам. Но для этого эти запросы должны по-настоящему «очеловечиться».

Информационные технологии, как и любые другие инструментальные новшества, не открывают светлой эры и не служат силам зла. В то же время они стоят особняком в ряду прогрессивных технологий. Если орудия и механизмы воздействовали на окружающую среду и только за счет ее (среды) изменений - на человека, то цифровые технологии нацелены и способны воздействовать непосредственно на сознание.

Новейшие технологии принципиально отличаются от всех прежних, характеризующихся более или менее узкой направленностью, и влияют на все сферы культуры. Еще важнее, что предшествовавшие технологии, главным образом, порождали перемены социальные, а информационные способны на эффективное индивидуальное, личностное воздействие.

Призыв, начертанный на храме Аполлона — «Познай самого себя» - в информационном обществе весьма актуален, как и во все времена. Познать, заглянуть в себя - это попытка понять, в чем состоят не животные, не социальные потребности, удовлетворение которых обеспечивали технологии традиционного и индустриального общества, а истинно человеческие.

Теория и практика сегодняшнего информационного общества определяются прагматичными ценностями в цифровом оформлении. Однако современный уровень прогресса уже формирует условия, достаточные для социального благополучия, а IT формируют платформу для смены приоритетов социальных, обеспечивавших тысячелетиями культурное выживание, на индивидуальные, создают серьезные предпосылки к тому, чтобы размыть дихотомическую узость традиционных ценностей и органично структурировать формы личностного существования в социуме. В многомиллиардном, массовом демократическом обществе это, возможно, единственный путь к трансформации культуры и человека.

$$
* * * *
$$


Культура в эволюционном движении всегда оставалась достаточно индифферентной кличностной реализации. Такое осуществление - удел фигур выдающихся, гениев, ярких талантов. Чем же отличаются эти герои? Возможно, в основе - уникальная способность к самооценке. Не в бытовых или общественных коллизиях, а в чутком, настойчивом, неустанном поиске призвания, предназначения.

Гений легко обойдется без цифровых достижений. Однако миллионам такое не под силу. Но компьютер - двойник, волшебное зеркало, глобальные сети, виртуальные расширения создает реальные предпосылки к тому, чтобы распознать задатки, склонности, примеряя самые разные искусства, науки, ремесла, языки или применяя к ним свой образ. На горизонтах, которые открывает самопознание, интегрируемое в культуру посредством информационнокоммуникационных технологий, появляется вожделенное общество знания.

\title{
Литература
}

[1] Inglehart R. Human Beliefs and Values: A Cross-Cultural Sourcebook based on the 1999-2002 values Surveys. Mexico City: Siglo XXI, 2004. In ed. M. Basanez, J. Deiz-Medrano, L. Halman and R. Luijkx.

[2] Белл Д. Грядущее постиндустриальное общество. Опыт социального прогнозирования. М.: Academia, 1999. $956 \mathrm{c}$.

[3] Drucker P. Post-Capitalist Society. Harper Business, N.-Y., 1993. 232 p.

[4] Иноземцев В. Расколотая цивилизация. М.: Academia, 1999. 724 c.

[5] Кастельс М. Власть коммуникаций. М.: НИУ ВШЭ, 2016. 568 с.

[6] Кравченко А.И. Культурология. М.: Академический проект, 2003. 496 с.

[7] Хейзинга Й. Homo Ludens. В тени завтрашнего дня. М.: Прогресс, 1992. 464 с.

[8] Инглегард Р. Культурный сдвиг в зрелом индустриальном обществе // Новая постиндустриальная волна на Западе / под ред. В.Л. Иноземцева. М.: Academia, 1999. С. 245-260.

[9] Дриккер А.С. Эволюция культуры: информационный отбор. СПб.: Академический проект, 2000. 184 c.

[10] Бэкон Ф. Новая Атлантида. М.: Изд-во Академии наук СССР, 1962.

[11] Тоффлер Э. Третья волна. М.: АСТ, 1999. 784 с.

[12] Гэлбрейт Дж. К. Новое индустриальное общество. М.: Прогресс, 1969. 480 с.

[13] Розенберг Н., Бирдиелл Л., мл. Как Запад стал богатым. Новосибирск: Экор, 1995. 352 c.

[14] Оруэлл Дж. Джеймс Бернем и революция менеджеров [Электронный ресурс] // URL: http://orwell.ru/library/reviews/bernham (дата обращения 15.10.2016).

[15] Захаров А.А. Муравей, семья, колония. М.: Наука, 1978. 141 с.

[16] Винер Н. Кибернетика и общество. М.: Изд-во иностранной литературы, 1958. 203 с.

[17] Venter J.C. Life at the Speed of Light: From the Double Helix to the Dawn of Digital Life. New York: Viking Adult, 2013.

[18] Kurzweil R. How to Create a Mind: The Secret of Human Thought Revealed. Penguin Books, 2013.

\section{Formation of Modern Information Ideals}

\author{
A. Drikker, E. Makovecky \\ Saint-Petersburg State University, Russia \\ a.drikker@spbu.ru, e.makovetsky@spbu.ru
}

\begin{abstract}
Today's ideal of the advanced progressive culture is an information ideal which propagandizes the future "society of knowledge". The development of information society is listed as one of the main goals in the constitutions of many states. However the analysis of post-industrial culture of the global world doesn't allow to find convincing signs of the proclaimed future, rather we can find obvious divergences of declarations and reality. The basic value of the computerized world is not knowledge but property, whose acquisition is now first of all connected with specific information, crucial for the mass operations management. The wrong interpretation of current trends is a result of reduction, which regards information and knowledge as synonyms. The ascending evolution is determined not by the amount of information but by the relevant information (Wiener), which can be
\end{abstract}


turned into knowledge. The effective forecast can't be constructed mainly on technological base. The culture evolution is cumulative result of social, psychological and technological processes.

At the same time Information Technologies are very special. The tools and mechanisms made impact on our environment and thus initiated social changes; digital technologies can directly affect human conscience. Nowadays ICT are laying the foundations for the replacement of social priorities by individual priorities and for the discovery of genuine human needs, previously concealed by animal and social needs satisfied by the technologies of traditional and industrial society. It is possible to see prevalence of computers, global networks, and virtual expansions as the termination of Ice Age. New digital "climatic" cultural conditions open a way to self-knowledge unattainable so far. Desired society of knowledge appears on the horizons of this self-knowledge.

Keywords: information and communication technologies; significant information; axiology; cultural evolution; post-industrial culture; information society.

\section{References}

[1] Inglehart R. Human Beliefs and Values: A Cross-Cultural Sourcebook based on the 1999-2002 values Surveys. Mexico City: Siglo XXI, 2004. In ed. M. Basanez, J. Deiz-Medrano, L. Halman and R. Luijkx.

[2] Bell D. Grjadushhee postindustrial'noe obshhestvo. Opyt social'nogo prognozirovanija. M.: Academia, 1999. $956 \mathrm{~s}$.

[3] Drucker P. Post-Capitalist Society. Harper Business, N.-Y., 1993. 232 p.

[4] Inozemcev V. Raskolotaja civilizacija. M.: Academia, 1999. 724 s.

[5] Kastel's M. Vlast' kommunikacij. M.: NIU VShJe, 2016. 568 s.

[6] Kravchenko A.I. Kul'turologija. M.: Akademicheskij proekt, 2003. $496 \mathrm{s.}$

[7] Hejzinga J. Homo Ludens. V teni zavtrashnego dnja. M.: Progress, 1992. $464 \mathrm{~s}$.

[8] Inglegard R. Kul'turnyj sdvig v zrelom industrial'nom obshhestve // Novaja postindustrial'naja volna na Zapade / pod red. V.L. Inozemceva. M.: Academia, 1999. S. 245-260.

[9] Drikker A.S. Jevoljucija kul'tury: informacionnyj otbor. SPb.: Akademicheskij proekt, 2000. $184 \mathrm{s.}$

[10] Bjekon F. Novaja Atlantida. M.: Izd-vo Akademii nauk SSSR, 1962.

[11] Toffler Je. Tret'ja volna. M.: AST, 1999. 784 s.

[12] Gjelbrejt Dzh. K. Novoe industrial'noe obshhestvo. M.: Progress, 1969. $480 \mathrm{~s}$.

[13] Rozenberg N., Birdiell L., ml. Kak Zapad stal bogatym. Novosibirsk: Jekor, 1995. 352 s.

[14] Orujell Dzh. Dzhejms Bernem i revoljucija menedzherov [Jelektronnyj resurs] // URL: http://orwell.ru/library/reviews/bernham (data obrashhenija 15.10.2016).

[15] Zaharov A.A. Muravej, sem'ja, kolonija. M.: Nauka, 1978. $141 \mathrm{s.}$

[16] Viner N. Kibernetika i obshhestvo. M.: Izd-vo inostrannoj literatury, 1958. 203 s.

[17] Venter J.C. Life at the Speed of Light: From the Double Helix to the Dawn of Digital Life. New York: Viking Adult, 2013.

[18] Kurzweil R. How to Create a Mind: The Secret of Human Thought Revealed. Penguin Books, 2013. 